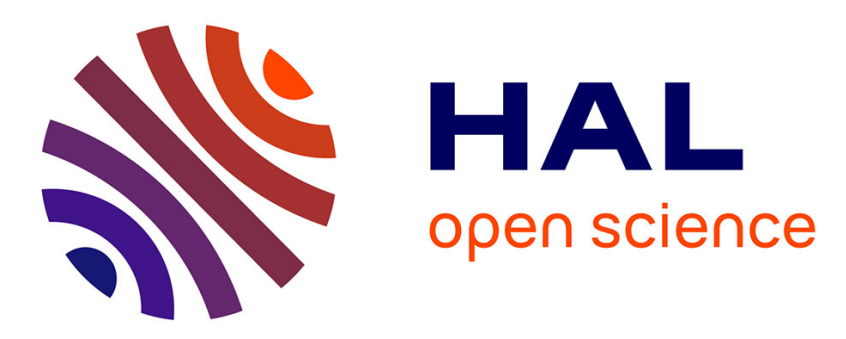

\title{
Local hydrodynamics investigation within a dynamic filtration unit under laminar flow
}

Xiaomin Xie, Nicolas Dietrich, Luc Fillaudeau, Claude Le Men, Philippe Schmitz, Alain Liné

\section{- To cite this version:}

Xiaomin Xie, Nicolas Dietrich, Luc Fillaudeau, Claude Le Men, Philippe Schmitz, et al.. Local hydrodynamics investigation within a dynamic filtration unit under laminar flow. Chemical Engineering Research and Design, 2018, 132, pp.954-965. 10.1016/j.cherd.2018.02.018 . hal-01886465

\section{HAL Id: hal-01886465 https://hal.science/hal-01886465}

Submitted on 19 Nov 2019

HAL is a multi-disciplinary open access archive for the deposit and dissemination of scientific research documents, whether they are published or not. The documents may come from teaching and research institutions in France or abroad, or from public or private research centers.
L'archive ouverte pluridisciplinaire $\mathbf{H A L}$, est destinée au dépôt et à la diffusion de documents scientifiques de niveau recherche, publiés ou non, émanant des établissements d'enseignement et de recherche français ou étrangers, des laboratoires publics ou privés. 
Local Hydrodynamics Investigation within a Dynamic Filtration Unit under Laminar Flow

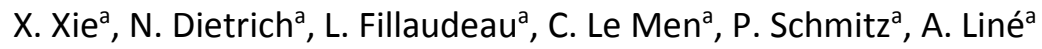

${ }^{a}$ Toulouse Univ., INSA-LISBP, 135 Avenue de Rangueil, 31077 Toulouse cedex, France.

Corresponding author: alain.line@insa-toulouse.fr

\section{Highlights}

- Instantaneous wall shear stress is investigated in laminar flow in a dynamic filtration unit

- Mean wall shear stress distribution is deduced from vertical profiles of mean tangential velocity

- Organized motions induced by impeller rotation are reconstructed by P.O.D. analysis of P.I.V. data

- Root mean squared fluctuating wall shear stress distribution is estimated and shown to have the same order of magnitude as the mean wall shear stress.

Abstract A dynamic filtration module, called a Rotating and Vibrating Filtration (R.V.F.) module, was designed and dedicated to the treatment of highly viscous fluid, such as fermentation broth or liquid food. To this end, an experimental study was undertaken, using a laminar flow regime with a viscous Newtonian model fluid in a dynamic filtration module in order to quantify the effect of local hydrodynamics on filtration. Instantaneous velocity fields can be measured and analyzed within an R.V.F. by using Particle Image Velocimetry (P.I.V.). In this study, we applied P.I.V. to study the laminar local hydrodynamics in 3 different slices within the $3 \mathrm{~mm}$ gap between the membrane and the impeller and 3 vertical slices at different radial positions, with rotation speeds from 0 to $10 \mathrm{~Hz}$. Radial and vertical profiles of tangential velocity were then plotted. Proper Orthogonal Decomposition (P.O.D.) was applied to the P.I.V. data to discriminate between mean flow and fluctuating velocities induced by the periodic motion of the impeller. Thus, viscous shear stress profiles were deduced in terms of both mean shear stress profile and root mean squared (r.m.s.) fluctuating shear stress profile; wall values were then deduced. With this approach, we were able to quantify the distribution of viscous shear stress at the wall (membrane), in terms of mean value and r.m.s. contribution. Dynamic filtration efficiency was thus enlightened by local hydrodynamics. 


\section{Keywords}

Hydrodynamics of Dynamic Filtration Unit, Wall shear stress and torque, Particle Image Velocimetry, Proper Orthogonal Decomposition

\section{Introduction}

Three phase reactors and, in particular, membrane bioreactors (MBR) appeared in the 1970s and have been largely applied in the biotechnology field: pharmaceutical and food industries, and white biotechnology. Increasing the cell density in bioreactors is useful to improve the overall productivity of fed-batch and continuous processes, particularly in biofuel production, which has to be competitive according to energy, economic and environmental criteria. The main constraints of membrane processes are related to material cost, energy consumption, fouling removal and permeate flux decline (Ersahin et al., 2012). Dynamic Filtration, also named Shear Enhanced Filtration, appears to be a promising alternative to conventional filtration methods (dead-end filtration, cross-flow filtration), which are currently not efficient enough. What makes this system different from the conventional filtration type is that, in the filtration cells, the system creates and enhances the shear rate at the membrane surface by means of a mechanical part, such as a disk rotating near a fixed membrane, or rotating or vibrating membranes.

In recent decades, many efforts have been made and studies performed to develop novel DF modules to enhance the shear rate at the membrane surface by changing the configuration of the filtration cells. A review of the existing dynamic filtration modules (Xie X., 2017) showed that they emanate from 30 companies and laboratories, exist at laboratory to industrial scales, and can be mainly classified according to the type of membrane (mobile or stationary) and the type of mechanical perturbation (rotating, vibrating, oscillating). 
Rotating cylindrical membrane, rotating flat membrane and vibrating flat and cylindrical membrane modules have been applied in bioprocesses and can be mentioned to illustrate the technological diversity. However, DF modules with stationary membranes form the basis of the most popular configurations, in which a mechanical device (impeller, cone, smooth disk or with promoters welded onto disk surface) rotates close to the membrane. The shear rate at the disk surface is influenced the gap between the rotor and the membrane, which has therefore become one of the most important points for researchers. Many rotating disk modules have been well documented in the literature, such as the Dynamic Membrane Filter (DMF, Pall Corp., Cortland, NY) (Frenander and Jönsson, 1996; Lee et al., 1995) and the RDM (Rotating Disk Module) (Akoum et al., 2006; Zhang and Ding, 2015). Applying a specially designed rotor was also very helpful in improving the system performance. Examples of such devices include: Cross Rotational Filters (CR-filters, Metso-Paper corp. Finland), (Huuhilo et al., 2001; Mänttäri et al., 1997), Rotating and Vibrating Filtration module (R.V.F. module, R.V.F. Filtration, Paris, France) (Fillaudeau et al., 2007; Rayess et al., 2016; XIE et al., 2017), the DYNO filter (Bokela GmbH, Karlsruhe, Germany) (Bott et al., 2000) and the FMX (BKT United, Korea) filter (Kim et al., 2015).

With such complex configurations, DF modules are able to generate high shear rates - up to approximately $1-3 \times 10^{5} \mathrm{~s}^{-1}$ on the membrane surface under low transmembrane pressure, TMP (Chang, 2008; Jaffrin et al., 2004). Shear rate is one of the crucial factors in the MBR process as it can control membrane fouling and enhance permeate flux. However, it also has a strong impact on biological media. Cell populations are known to be sensitive to the physicochemical environment, including local viscous dissipation and mechanical stresses (magnitude, fluctuation, duration), which may induce a metabolism switch to cell lysis. It is thus important to characterize the flow pattern and to quantify the velocity fields, pressure and parietal shear stresses at the membrane surface locally and instantaneously, as they are linked to the operating conditions and the evolution of the rheological behavior of the fermentation broth. The flow pattern results from the complexity of the geometrical 
configuration, the rheological behavior, and the operating conditions. It also depends on the time and length scales.

\section{P.I.V. and P.O.D.}

P.I.V. is an efficient technique for investigating local and instantaneous velocity fields. It is based on the visualization of tracer particles displacement to estimate the flow velocity. P.I.V. provides instantaneous vector maps by tracking the particle displacement in a given time interval. In the DF filtration domain, P.I.V. measurement was first applied in rotating cylindrical filters (Rudolph et al., 1998; Wereley \& Lueptow, 1999; Wereley et al., 2002), where it gave details of particle paths and streamlines in different dimensions and geometrical profiles. This helped to explain the physical fouling mechanism due to the cylindrical Couette flow and the Taylor vortex flow. Figueredo-Cardero et al. (2012) examined the flow field in a thin gap between two cylinders, mainly focusing on the radial behavior. Other P.I.V .measurements have been made with a rotating cone filter (Francis et al., 2006), a rotating flat-sheet (wing-like) membrane bioreactor (Jiang et al., 2013 a \& b), a vibrating hollow fiber filter (Li et al., 2013), and a folded plate membrane module (Zhang et al., 2015) in order to better explain their filter performances by analyzing flow motion. In the present study, the P.I.V. technique was used to investigate local hydrodynamics.

Recently, the P.O.D. (Proper Orthogonal Decomposition) technique has been used to extract more and more information from such huge sources of experimental data (Moreau \& Liné, 2006, Doulgerakis et al., 2010 \& 2011, Liné et al., 2013, Liné, 2016). P.O.D. is an efficient technique to process instantaneous velocity fields. It enables the velocity to be reconstructed in terms of summation of modes, each mode contributing to the total kinetic energy. P.O.D. is thus a modal decomposition of instantaneous velocity fields.

Based on statistics of instantaneous 2D velocity fields, P.O.D. can generate a series of eigenvalues and eigenvectors. In the following, $\lambda^{(I)}$ is the $t^{\text {th }}$ eigenvalue and $\overrightarrow{\Phi^{(I)}}(x, y)$ is the $t^{\text {th }}$ associated eigenfunction or eigenvector. Each instantaneous velocity field can be reconstructed as: 


$$
\overrightarrow{V_{k}}(x, y)=\sum_{I=1}^{N} a_{k}^{(I)} \overrightarrow{\Phi^{(I)}}(x, y)
$$

where $l$ is the $I^{\text {th }}$ mode of P.O.D. (total mode number equal to $N$ ), while $a_{k}^{(I)}$ is the corresponding P.O.D. coefficient. The series of coefficients $a_{k}^{(I)}$ (or $a^{(I)}(t)$ in the case of resolved P.I.V.) is given by the projection of each instantaneous velocity field on the $\mathrm{I}^{\text {th }}$ eigenvector:

$$
a_{k}^{(I)}=\left(\overrightarrow{V_{k}}, \overrightarrow{\Phi^{(I)}}\right)
$$

It is possible to reconstruct the velocity field and, in particular, the mean flow and the organized motion.

P.I.V. measurements were performed in a 2-D plane here, $x-y$ for example, on a regular mesh with $\mathrm{L}$ rows and $C$ columns, leading to $L X C$ points per plane. Each instantaneous velocity field measurement provided a snapshot of the flow. The statistical analysis was performed on $N$ snapshots taken in the same plane (P.I.V. data). The number of grid points being $L X C$, the matrix of instantaneous velocity vector data was obtained as:

$$
\left[\begin{array}{lll}
\overrightarrow{U_{k}}\left(x_{1}, y_{1}\right) & \overrightarrow{U_{k}}\left(x_{1}, y_{2}\right) & \overrightarrow{U_{k}}\left(x_{1}, y_{C}\right) \\
\overrightarrow{U_{k}}\left(x_{2}, y_{1}\right) & \overrightarrow{U_{k}}\left(x_{2}, y_{2}\right) & \overrightarrow{U_{k}}\left(x_{2}, y_{C}\right) \\
\overrightarrow{U_{k}}\left(x_{L}, y_{1}\right) & \overrightarrow{U_{k}}\left(x_{L}, y_{2}\right) & \overrightarrow{U_{k}}\left(x_{L}, y_{C}\right)
\end{array}\right]
$$

where $k$ is the index of the instantaneous event $(k=1, N)$. This matrix of vectors can be reshaped to build a vector $\overrightarrow{U_{k}}$ with $2 L x C$ rows as follows:

$$
\overrightarrow{U_{k}}=\left[\begin{array}{c}
u_{k}\left(x_{1}, y_{1}\right) \\
u_{k}\left(x_{2}, y_{1}\right) \\
u_{k}\left(x_{L}, y_{C}\right) \\
v_{k}\left(x_{1}, y_{1}\right) \\
v_{k}\left(x_{2}, y_{1}\right) \\
v_{k}\left(x_{L}, y_{C}\right)
\end{array}\right]
$$

The snapshot method adopted in this eigenvalue problem was proposed by Sirovich (1987). This method is based on the snapshot matrix $M$ corresponding to the $N$ instantaneous velocity fields. The matrix $M$ can be expressed as 


$$
M=\left[\begin{array}{cccc}
u_{1}\left(x_{1}, y_{1}\right) & u_{2}\left(x_{1}, y_{1}\right) & \ldots & u_{N}\left(x_{1}, y_{1}\right) \\
u_{1}\left(x_{2}, y_{1}\right) & u_{2}\left(x_{2}, y_{1}\right) & \ldots & u_{N}\left(x_{2}, y_{1}\right) \\
& & \ldots & \\
u_{1}\left(x_{L}, y_{C}\right) & u_{2}\left(x_{L}, y_{C}\right) & \ldots & u_{N}\left(x_{L}, y_{C}\right) \\
v_{1}\left(x_{1}, y_{1}\right) & v_{2}\left(x_{1}, y_{1}\right) & \ldots & v_{N}\left(x_{1}, y_{1}\right) \\
v_{1}\left(x_{2}, y_{1}\right) & v_{2}\left(x_{2}, y_{1}\right) & \ldots & v_{N}\left(x_{2}, y_{1}\right) \\
& & \ldots & \\
v_{1}\left(x_{L}, y_{C}\right) & v_{2}\left(x_{L}, y_{C}\right) & \ldots & v_{N}\left(x_{L}, y_{C}\right)
\end{array}\right]
$$

The matrix $M$ has $2 L C$ rows and $N$ columns, each column of the matrix $M$ representing the $k^{\text {th }}$ event of the instantaneous velocity field. The auto-covariance tensor $\mathrm{R}$ can be derived as:

$$
R=\frac{1}{N} M \cdot M^{T}=\left[\begin{array}{lll}
\overline{u^{2}\left(x_{1}, y_{1}\right)} & & \\
& \cdots & \\
& & \overline{v^{2}\left(x_{L}, y_{C}\right)}
\end{array}\right]
$$

Modes can be derived from eigenvalue equation, adapted by Sirovich (1987) as:

$$
R\left(x, y, x^{\prime}, y^{\prime}\right) \overrightarrow{\Phi^{(I)}}\left(x^{\prime}, y^{\prime}\right)=\lambda^{(I)} \overrightarrow{\Phi^{(I)}}(x, y)
$$

where $R$ is the cross-correlation tensor and $\lambda^{(I)}$ are the eigenvalues. In the present problem, the eigenvalues are expressed in $\mathrm{m}^{2} / \mathrm{s}^{2} . \overrightarrow{\Phi^{(I)}}(x, y)$ is a spatial eigenfunction associated with the $t^{\text {th }}$ mode. Eigenvalue series are usually ranked in decreasing order.

\section{Experiments}

A specific R.V.F. module was designed to perform the velocity measurement by the P.I.V. technique. It consisted of two filtration cells in series, including two flat disc membranes fixed onto porous substrates in the vicinity of a three-blade impeller attached to a central shaft. The top part of the module was made of transparent P.M.M.A. (Poly-methyl methacrylate) polymer so that the flow could be visualized as shown in Figure 1. The R.V.F. module was integrated in a fully instrumented closed circulation loop. 


\subsection{Dynamic filtration unit}

The transparent R.V.F. laboratory module consisted of two identical filtration cells in series (2 membranes in total, filtration area $0.048 \mathrm{~m}^{2}$, volume $0.2 \mathrm{~L}$ per cell, $1.5 \mathrm{~L}$ in total). The two cells were installed with a three-blade impeller (flat blade, diameter $=138 \mathrm{~mm}$, thickness $=8 \mathrm{~mm}$ ) driven by a central shaft continuously rotating (up to $50 \mathrm{~Hz}$ ) in a $14 \mathrm{~mm}$ gap between two porous substrate plates (membrane support in metal) which drained the permeate. This configuration gave a $3 \mathrm{~mm}$ gap between the impeller and the membrane surface. This simple mechanical device was run continuously (rotating effect) and generated a high, intermittent shear stress in the small gap (transmembrane pressure (TMP) up to $300 \mathrm{kPa}$ ). Pressure oscillations (vibrating effect) were generated by the trailing and leading edges of each blade. The rotation frequency could be adjusted to optimize the operating conditions.

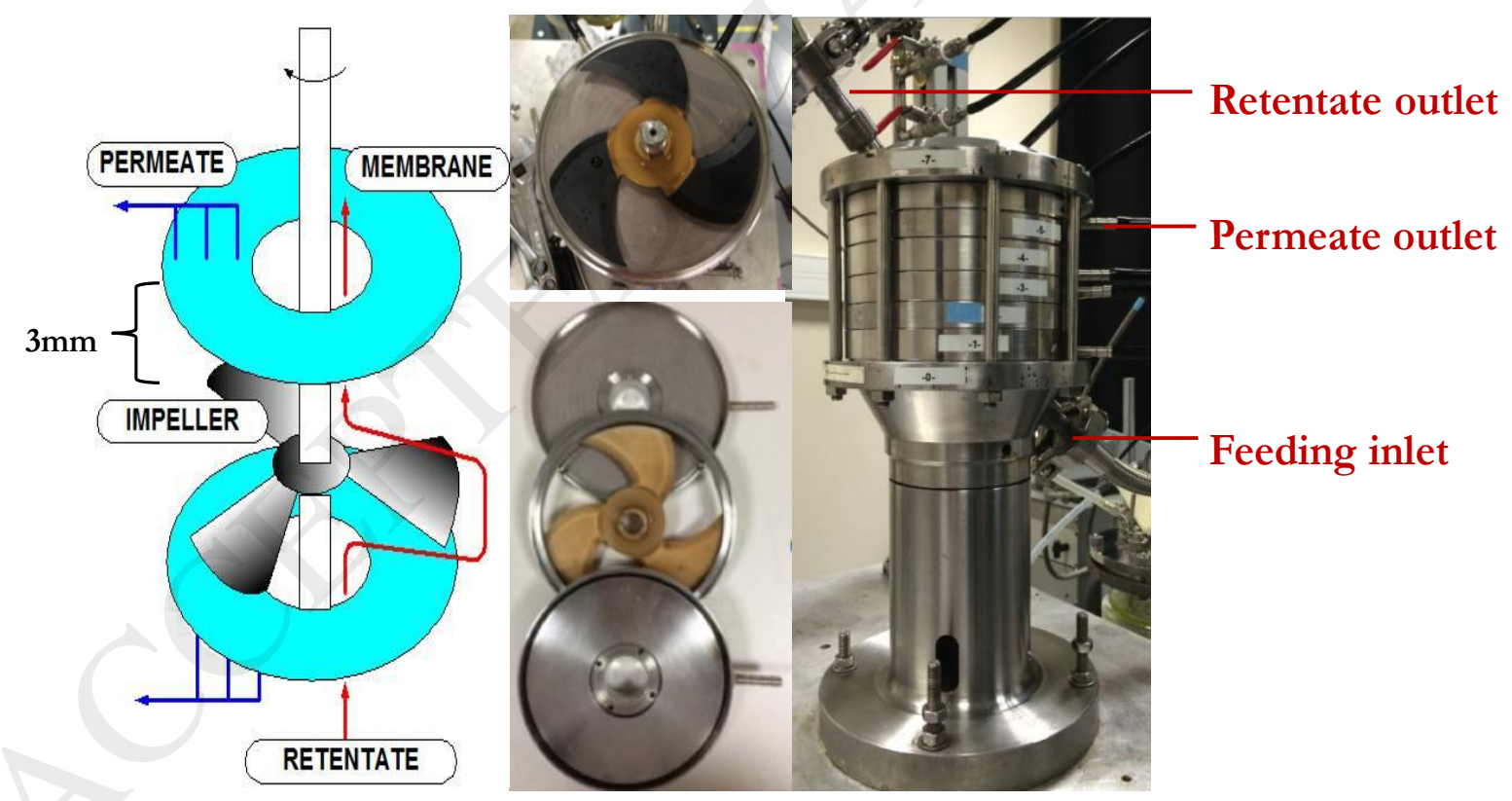

Figure 1. Technical design of the R.V.F. filtration cell (Unit: $\mathrm{mm}$ ) and illustration of top-view of transparent device used during P.I.V. measurements.

A power consumption curve represents power number $N_{P}=P /\left(\rho N^{3} d^{5}\right)$ against $\operatorname{Re}_{\text {mixing }}$ and is an important specification to evaluate agitation and mixing performance by considering the device 
properties and the fluid rheological properties. The power consumption curve (shown in Figure 2) of the R.V.F. module was obtained previously (Fillaudeau et al., 2007), to identify the flow regime of given operating conditions.

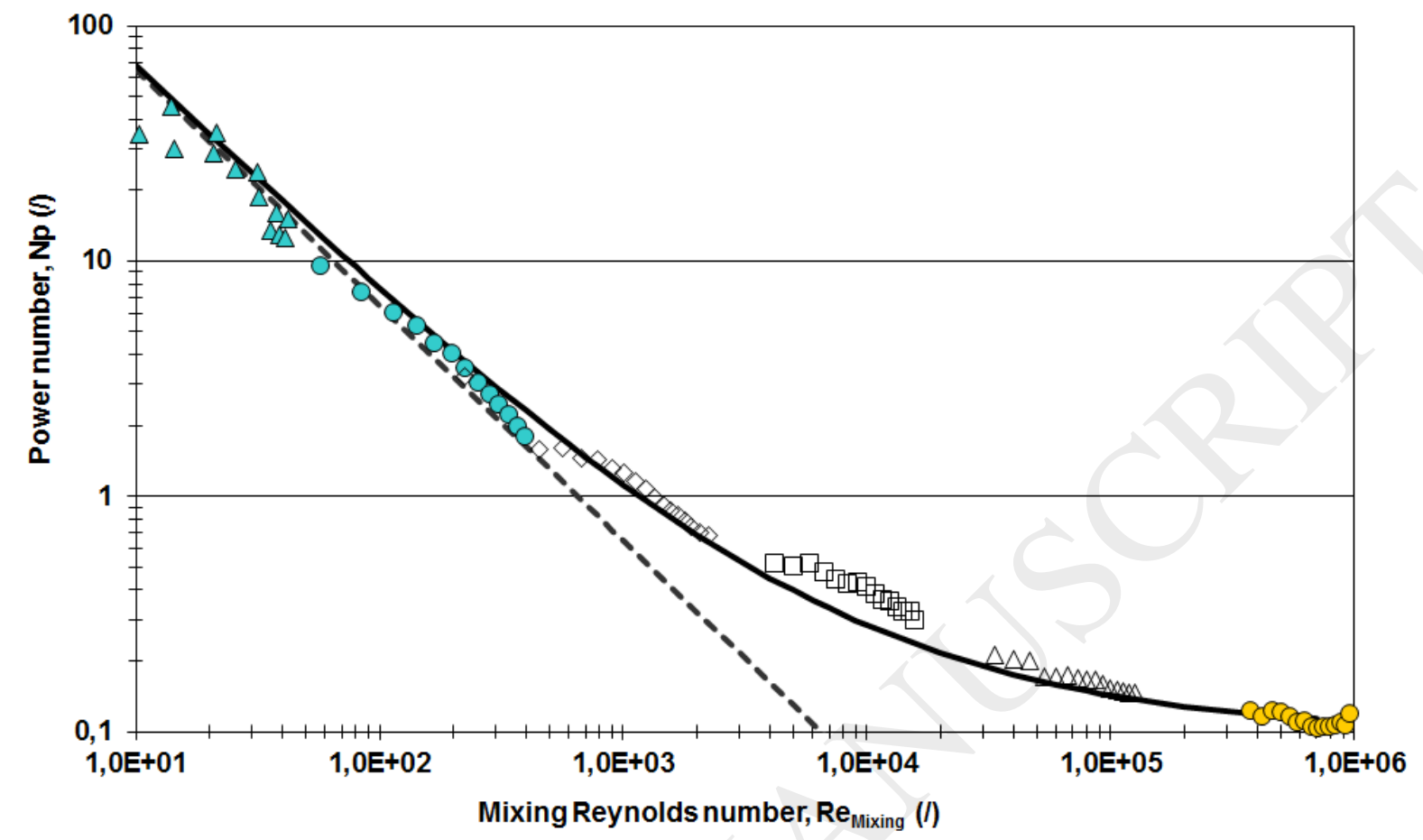

Figure 2. Power consumption curve established with R.V.F. lab-scale module by Fillaudeau et al., 2007. $\Delta$ Glucose (5.5 Pa.s) • Glucose (1.2 Pa.s) $\diamond$ Sucrose (0.3 Pa.s) $\square$ Sucrose (0.05 Pa.s) $\Delta$ Sucrose (0.008 Pa.s) • Water (0.001 Pa.s)

\subsection{P.I.V. material and methods}

Rhodamine B fluorescent polymer particles (FPP-RhB-10, 1-20 $\mu \mathrm{m}$, DANTEC DYNAMICS) were used because they give a homogeneous distribution and have good ability to represent the flow motion and scatter the light from laser beams in a fluid. Particles are spherical with a mean particle diameter of 10 $\mu \mathrm{m}$ (range $1-20 \mu \mathrm{m}$ ), a density of $1190 \mathrm{~kg} / \mathrm{m}^{3}$ and a refractive index of 1.479 . Pretreatment was conducted with sonication (Elmasonic $\mathrm{S} 60 \mathrm{H}, 50 / 60 \mathrm{~Hz}$ ) to deagglomerate the particles in the test fluid (water and Breox solutions).

In the horizontal set-up, the R.V.F. module was integrated in the P.I.V. system. In this study, measurements were focused on the horizontal plane ( $x-y$ plane) between the upper wall (of the filtration cell) and the impeller surface, and the laser sheet could be adjusted to different slices $\left(z_{1}-z_{8}\right)$. A Cartesian coordinate system was defined by $z=0$ at the upper membrane and $x=0, y=0$ at the center 
of the mixing shaft. The P.I.V. system was supported and maintained by DANTEC DYNAMICS Co. (Denmark). The basic elements required were:

- A pulsed laser LISTRON L200-15 P.I.V. (Repetition Rate 0-15 Hz, not time resolved, Max output Energy at 532nm $200 \mathrm{~mJ}$, pulse duration $4 \mathrm{~ns}$, laser medium)

- A transparent filtration cell replacing the standard stainless-steel cell;

- A laser sheet generator to illuminate the target plane and the fluorescent particles;

- A CCD camera (Dantec Dynamic Flowsense E0 4M 2048×2048 pixels ${ }^{2}$ ) focused on the target plane (i.e. the laser sheet);

- A high-pass red filter ( $>570 \mathrm{~nm}$ ) placed in front of the camera to allow only fluorescent light (from particles) to be detected by the camera, while filtering out reflection from the transparent cell (since tracers were used in this case);

- A processor to communicate with the camera and the pulsed laser.

In the vertical set-up, the basic elements of P.I.V. measurement were the same but the horizontal laser sheet was reflected by a mirror and oriented towards the vertical direction ( $z$ direction) at 3 radial positions. The CCD camera was set perpendicularly to the vertical target plane.

The experimental strategy can be summarized as follows:

- For horizontal measurements, the laser sheet was adjusted by $0.5 \mathrm{~mm}$ steps in the $z$ direction from $z_{1}$ to $z_{6}$. From the wall to the impeller, $z_{1}=0.25 \mathrm{~mm}, z_{2}=0.75 \mathrm{~mm}, z_{3}=1.25 \mathrm{~mm}, z_{4}=1.75$ $\mathrm{mm}, z_{5}=2.25 \mathrm{~mm}, z_{6}=2.75 \mathrm{~mm}$, with an uncertainty of $\pm 0.25 \mathrm{~mm}$ according to the thickness of the laser sheet. Two additional slices were scrutinized at $z_{7}=4.75 \mathrm{~mm}$ and $z_{8}=6.75 \mathrm{~mm}$ in order to access velocity fields between two blades;

- For vertical measurements, the laser sheet was adjusted to $r=30 \mathrm{~mm}, r=45 \mathrm{~mm}$ and $r=65$ $\mathrm{mm}$.

The experiment was performed in a field of view of $109 \times 109 \mathrm{~mm}^{2}$ and focused on half of the filtration cell in the $x-y$ (horizontal) plane. This area captured more than one leading edge and one trailing edge. The flow field was assumed to be periodic since it was agitated by a 3-blade impeller. This half area was considered to represent the whole filtration cell. The raw image processing was evaluated using the commercial software DynamicStudio.2015a (DANTEC DYNAMIC, Denmark). A statistical adaptive cross-correlation algorithm was used to measure the displacement of particles. A mask was used to filter out the area that was not of interest and was iteratively adjusted to determine an Interrogation Area (IA) having a size and shape appropriate to the local seeding density and flow gradient (according to specified criteria). The initial adaptive IA window had $16 \times 16 \mathrm{px}^{2}$ to $32 \times 32 \mathrm{px}^{2}$ window for the 
calculation, corresponding to $0.85 \times 0.85 \mathrm{~mm}^{2}$ and $1.70 \times 1.70 \mathrm{~mm}^{2}$. A $50 \%$ overlap between windows was also applied to improve sampling. Therefore, theoretically, each velocity map had $128 \times 128$ vectors, with about 9000 valid and 7389 disabled by the mask, once approximately $1 \%$ bad vectors had been rejected. The time interval between the two images in each pair was controlled at between 500$800 \mu \mathrm{sec}$ depending on the operating conditions. This allowed the particle to move by approximately only a quarter of the window size. Other parameters can be found in Table 1 and 2 .

Table 1 Acquisition parameters of P.I.V. system (horizontal measurement)

\begin{tabular}{ll}
\hline Parameters & Setting \\
\hline Calibration & Scale factor: $7.177 ; 1$ pixel= $7.177 \times 7.4=53 \mu \mathrm{m}$ \\
Image size & $2048 \times 2048 \mathrm{px}^{2}\left(108 \times 108 \mathrm{~mm}^{2}\right), 128 \times 128$ vectors $(16384)$ \\
Interrogation window & adaptive P.I.V. from $16 \times 16 \mathrm{px}^{2}$ to $32 \times 32 \mathrm{px}^{2}$, step size $16 \times 16 \mathrm{px}^{2}$ \\
Particle density & $5-10$ particles per interrogation window $(16 \mathrm{px} \times 16 \mathrm{px})$ \\
Particle size & Mean diameter: $10-20 \mu \mathrm{m}$ \\
Time interval between consecutive & $500-800 \mu \mathrm{sec}$ \\
images, $\Delta \mathrm{t}$ & 1000 image pairs \\
Number of samples & \\
\hline
\end{tabular}

Table 2 Acquisition parameters of P.I.V. system (vertical measurement)

\begin{tabular}{ll}
\hline Parameters & Setting \\
\hline Calibration & Scale factor: $2.166 ; 1$ pixel $=2.166 \times 7.4=16 \mu \mathrm{m}$ \\
Image size & $2048 \times 944 \mathrm{px} 2\left(32.8 \times 15.1 \mathrm{~mm}^{2}\right), 128 \times 59$ vectors $(7552)$ \\
Interrogation window & adaptive P.I.V. from $16 \times 16 \mathrm{px}^{2}$ to $32 \times 32 \mathrm{px}^{2}$, step size $16 \times 16 \mathrm{px}^{2}$ \\
Particle density & $2-5$ particles per interrogation window $(16 \mathrm{px} \times 16 \mathrm{px})$ \\
Particle size & Mean diameter: $10-20 \mu \mathrm{m}$ \\
Calibration & Scale factor: $2.166 ; 1$ pixel $=2.166 \times 7.4=16 \mu \mathrm{m}$ \\
Time interval between consecutive & $10-300 \mu$ sec (depending on the individual case) \\
images, $\Delta \mathrm{t}$ & 3000 image pairs \\
Number of samples & \\
\hline
\end{tabular}

The proper number of images for the flow statistics (mean values and standard deviation) was investigated by plotting the moving average of velocity, in order to determine and optimize P.I.V. measurements. The reliability and stability of velocity fields were verified to determine to the minimum number of image pairs required. 


\subsection{Fluids}

Experiments were conducted in a water soluble, viscous, transparent Newtonian fluid $\left(\mathrm{Breox}^{\circledR}\right.$ Polyalkylene Glycol 75 W 55000, BASF) at the concentration of $40 \%(w / w)$ in water. All experiments were carried out at a constant temperature of $20^{\circ} \mathrm{C}$ and nominal flowrate of $50 \mathrm{~L} / \mathrm{h}$. The thermophysical properties: viscosity $\left(\mu=0.85\right.$ Pa.s) and density $\left(\rho=1067 \mathrm{~kg} / \mathrm{m}^{3}\right)$, were measured with a rheometer (HAAKE Mars III, Thermo Scientific, Germany) and a density meter (DE40, Mettler Toledo, France), respectively, at $\mathrm{T}=20^{\circ} \mathrm{C}$.

\section{Results and discussion concerning laminar flow}

In this paper, only laminar flow is investigated. Since an impeller was used, it is essential to account for the velocity fluctuations induced by its periodic motion. Thus, in laminar flow, a decomposition of the instantaneous velocity has to be considered as:

$V_{i}=\bar{V}_{l}+\widetilde{v}_{l}$

where $V_{i}$ is the instantaneous velocity component, $\bar{V}_{l}$ is the mean velocity (organized fluctuations are filtered out), and $\widetilde{v_{l}}$ is the transient (periodic or organized) fluctuation induced by the impeller blade. The mean value is obtained by ensemble averaging.

In a first step, mean flow will be considered. Both vertical and radial profiles of tangential velocities will be presented and discussed. Based on these mean velocity profiles, viscous shear stress profiles will be plotted and wall shear stress distributions will be derived. Finally, torque and power will be investigated. In a second step, organized motion induced by the impeller motion will be analyzed by the P.O.D. method. The eigenvalue spectrum indicating the contribution of each P.O.D. mode to the total kinetic energy will be plotted. The organized velocity field will be reconstructed. The associated root mean square wall shear stress will be estimated and results will be discussed. 


\subsection{Velocity and shear stress profiles}

The case presented here corresponds to a viscous fluid $\left(\rho=1067 \mathrm{~kg} / \mathrm{m}^{3} ; \mu=0.85\right.$ Pa.s) and a low frequency $(\mathrm{N}=2 \mathrm{~Hz})$. Thus the Reynolds number is:

$$
R e_{\text {mixing }}=\frac{\rho N D_{m}^{2}}{\mu}=42
$$

Three horizontal planes $(z=0.25,1.5$ and $2.75 \mathrm{~mm}$ from the upper wall) and three vertical ones $(r=30$, 45 and $65 \mathrm{~mm}$ ) investigated by P.I.V. are presented. The radial and vertical profiles of tangential mean velocities are plotted in Figure 3.

The three radial profiles are discussed first (Figure $3(a), z=0.25,1.5$ and $2.75 \mathrm{~mm}$ from the upper wall). The tangential mean velocity increases with radial position up to a maximum, then decreases towards the static external wall. The maximum velocity decreases from a high value close to the impeller $(0.52$ $\mathrm{m} / \mathrm{s}$ at $\mathrm{z}=2.75 \mathrm{~mm}$ from the upper wall $)$ to an intermediate value in the middle plane $(0.32 \mathrm{~m} / \mathrm{s}$ at $\mathrm{z}=$ $1.5 \mathrm{~mm}$ from the upper wall) and a low value close to the upper static wall $(0.12 \mathrm{~m} / \mathrm{s}$ at $\mathrm{z}=0.25 \mathrm{~mm}$ from the upper wall). In the region where the radial profile is linear, the vorticity is almost constant.

The three vertical profiles of tangential mean velocities are almost linear (Figure 3(b), r= 30, 45 and 65 $\mathrm{mm}$ ). The impeller velocities at the three radial positions are respectively $0.38,0.56$ and $0.81 \mathrm{~m} / \mathrm{s}$ while the liquid velocities measured close to the impeller $(z=3 \mathrm{~mm}$ from the upper wall) are close to 0.2 , 0.35 and $0.40 \mathrm{~m} / \mathrm{s}$. Consequently, the liquid mean velocity field is quite simple; because of the vertical confinement ( $3 \mathrm{~mm}$ gap between the impeller and the upper wall), it is a Couette type shear flow (linear vertical profile). In the region where the radial profiles are linear, the vorticity is almost constant. 


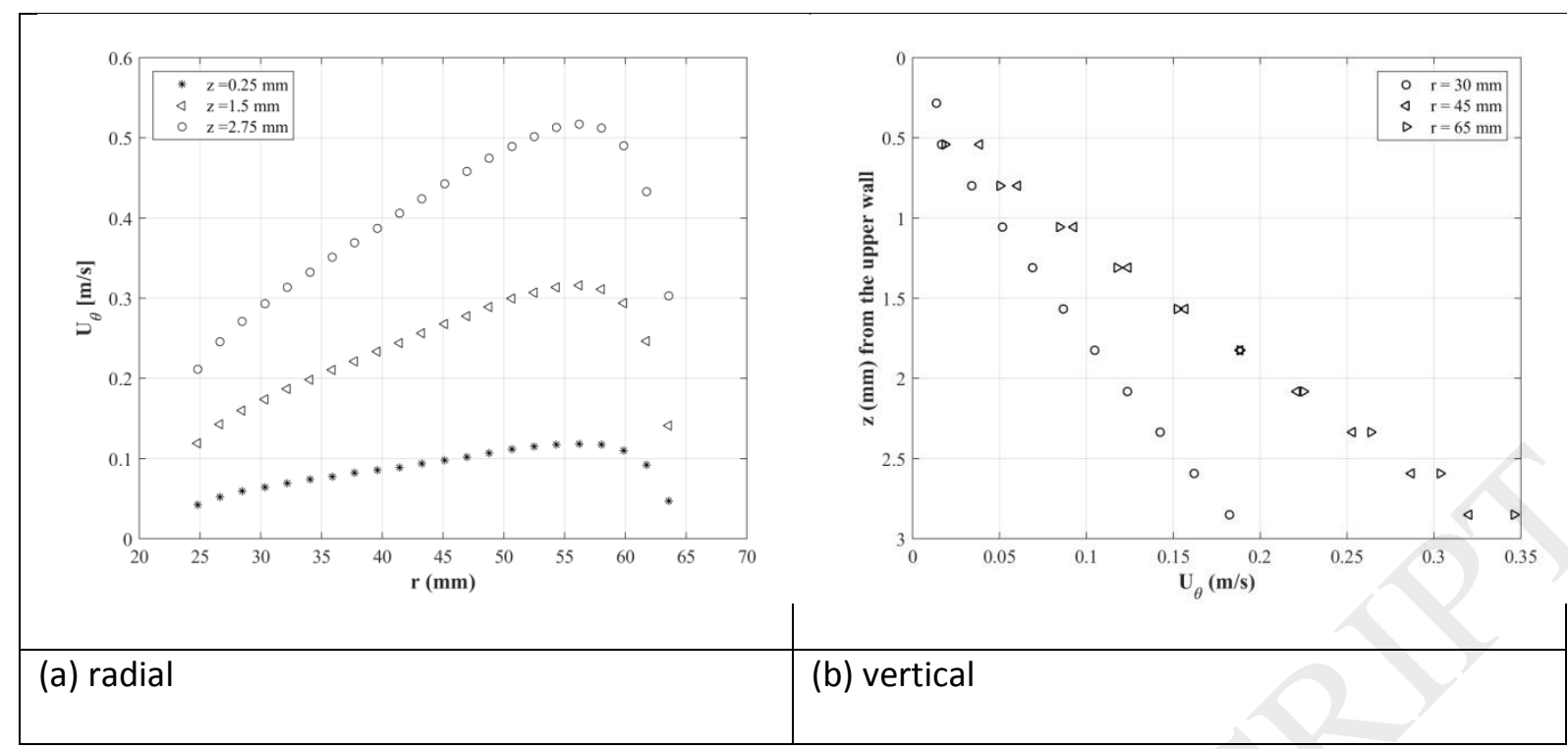

Figure 3. Evolution of radial and vertical profiles of mean tangential velocity profiles as a function of radial (a) and vertical (b) positions (Operating conditions: $\mathrm{Q}=50 \mathrm{~L} / \mathrm{h}$, fluid: Breox $40 \% \mathrm{w} / \mathrm{w}, \mu=$ 0.85 Pa.s, $\operatorname{Re}_{\text {Mixing }}=42$, and $\mathrm{T}=20^{\circ} \mathrm{C}$ ).

From these radial mean velocity profiles obtained from horizontal plane measurements, it is possible to estimate the radial profile of viscous shear stress for $24<\mathrm{r}<71 \mathrm{~mm}$ :

$$
\overline{\tau_{r \theta}}(r)=\mu r \frac{\partial}{\partial r}\left(\overline{\frac{V_{\theta}}{r}}\right)
$$

Once again, in the region where the radial profiles are linear, the viscous shear stress is almost zero, whereas it increases in wall regions. The mean shear stress at the external wall $(r=R e)$ can be estimated from each profile. Near the upper wall of the cell, the shear stress at the external wall is low (equal to $25 \mathrm{~Pa}$ ). In the middle plane, the shear stress at the external wall is higher (equal to $75 \mathrm{~Pa}$ ) whereas close to the impeller, it is highest and equal to $150 \mathrm{~Pa}$.

Thus, the torque resulting from the distribution of viscous shear stress along the external cylinder can be estimated above and below the impeller, assuming a mean value of $\tau_{\text {extcyl }} l_{\text {upper }}=75 \mathrm{~Pa}$ :

$$
T_{\text {extcyl }}{ }_{\text {upper }}=2 \pi R_{e} H_{u} \tau_{\text {extcyl }} R_{\text {upper }} R_{e}=7.1 \mathrm{mN} . \mathrm{m}
$$


The same torque is applied along the external cylinder below the impeller:

$$
T_{\text {extcyl }} \text { lower }=2 \pi R_{e} H_{l} \tau_{\text {extcyl }} \text { lower }_{e} R_{e}=7.1 \mathrm{mN} . \mathrm{m}
$$

The shear stress at the external cylinder can be considered constant and equal to $\tau_{\text {extcyl }}$ impeller $=$ $150 \mathrm{~Pa}$ in the region of the impeller. The torque is thus:

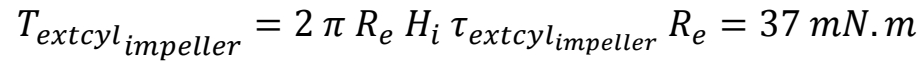

Consequently, the total torque along the external cylinder is

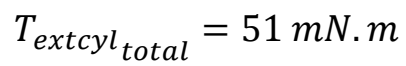

Clearly, the vertical profiles measured in the $3 \mathrm{~mm}$ gap above the impeller are quasi-linear. The velocity is zero at the static wall. Close to the impeller, it is maximum and probably proportional to the local velocity of the impeller.

Vertical profiles of the mean tangential velocity are plotted in Figure 3(b). They are almost linear. From these plots, the vertical profiles of viscous shear stress can be deduced and the viscous shear stress at the upper wall estimated (Figure 4). Close to the upper wall, some inaccuracy may appear (see $r=45$ $\mathrm{mm}$ ) due to the difficulty of measuring the velocity with P.I.V. close to a wall.

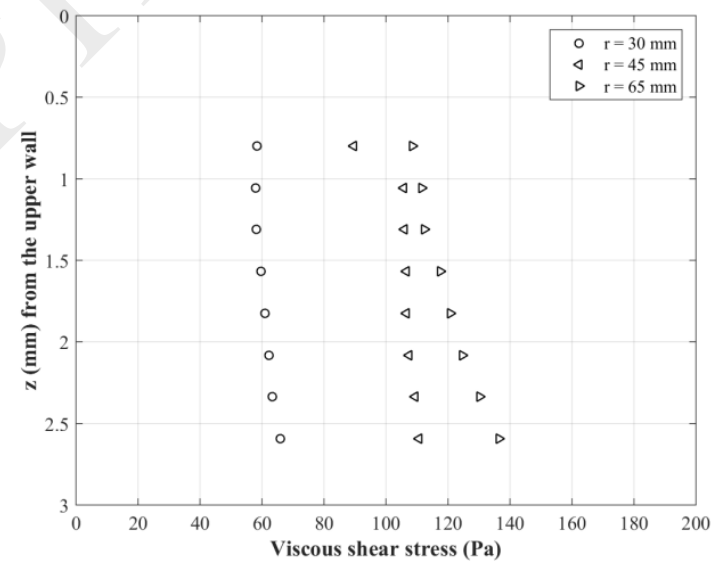


Figure 4. Vertical profiles of viscous shear stress Evolution of vertical profiles of viscous mean shear stress at 3 radial positions $(r=30,45$ and $65 \mathrm{~mm}$ ), with $\mathrm{N}=2 \mathrm{~Hz}$ (Operating conditions: $\mathrm{Q}=50$ L/h, fluid: Breox40\%w/w, $\mu=0.85$ Pa.s, Re Mixing $=42$ and 210 and $T=20^{\circ} \mathrm{C}$ )

Clearly, the radial profile of wall viscous shear stress is linear. One can (over)estimate it from

$$
\overline{\tau_{\theta z}}(r)=\mu \frac{\partial \overline{U_{\theta}}}{\partial z} \cong \mu \frac{(r 2 \pi N)}{H_{u}}
$$

At $\mathrm{N}=2 \mathrm{~Hz}$, we have:

$$
\overline{\tau_{\theta z}}(r) \cong \mu \frac{(r 2 \pi N)}{H_{u}}=1760 r
$$

At $r=65 \mathrm{~mm}$, this gives $115 \mathrm{~Pa}$.

Thus the torque at the upper wall can be estimated:

$$
T_{\text {upperwall }}=2 \pi \int_{R_{i}}^{R_{e}} \overline{\tau_{\theta z}}(r) r^{2} d r=2 \pi^{2} \mu \frac{N}{H_{u}} \int_{R_{i}}^{R_{e}} r^{3} d r \cong \frac{\pi^{2} \mu N R_{e}^{4}}{2 H_{u}}=0.134 \text { N.m }
$$

The same torque is exerted on the lower wall. Thus the total torque is:

$T_{\text {total }}=0.051+2 \times 0.134=0.32 \mathrm{~N} . \mathrm{m}$

An equal torque is exerted along the rotating impeller and shaft, so the power needed to rotate the impeller and shaft can be estimated:

Power $=T_{\text {total }} 2 \pi N=4 \mathrm{~W}$

It corresponds to a power number

$N_{P}=\frac{\text { Power }}{\rho N^{3} D_{m}^{5}}=13$

This value is relatively close to the power number measured in the first part of this work and plotted in Figure 2. It is important to underline that the main contribution to the torque is related to the shear 
along the upper and lower walls, where the membranes are installed. These results concern the mean flow. However, the impeller induces periodic fluctuations that will be investigated in the next subsection.

\subsection{P.O.D. analysis}

In order to extract the organized motion induced by the 3 blade impeller, P.O.D. is applied to P.I.V. data. First, the P.I.V. data obtained in horizontal planes will be processed to find the radial profile of fluctuating tangential velocities and then the P.I.V. data for vertical planes will be processed.

\section{Radial profile of fluctuating tangential velocity}

The eigenvalue spectrum is plotted in Figure 5. These eigenvalues are normalized by the sum of the eigenvalues (the total measured kinetic energy) and their spectrum is plotted as a function of mode number. Such normalized eigenvalues correspond to the contribution of each mode to the total kinetic energy in the plane of measurement. The contribution of the first mode to the total kinetic energy is dominant, at about $90 \%$. It corresponds to the mean flow. Considering the 4 following modes, it is easy to observe that eigenvalues 2 and 3 and eigenvalues 4 and 5 are close to each other. This means that the contribution of modes 2 and 3 to the kinetic energy is similar, and the same holds for modes 4 and 5 . They contribute several percent and less than 1\%, respectively, of the total kinetic energy. These 4 modes are likely associated with organized motions generated by the rotation of the impeller blades.

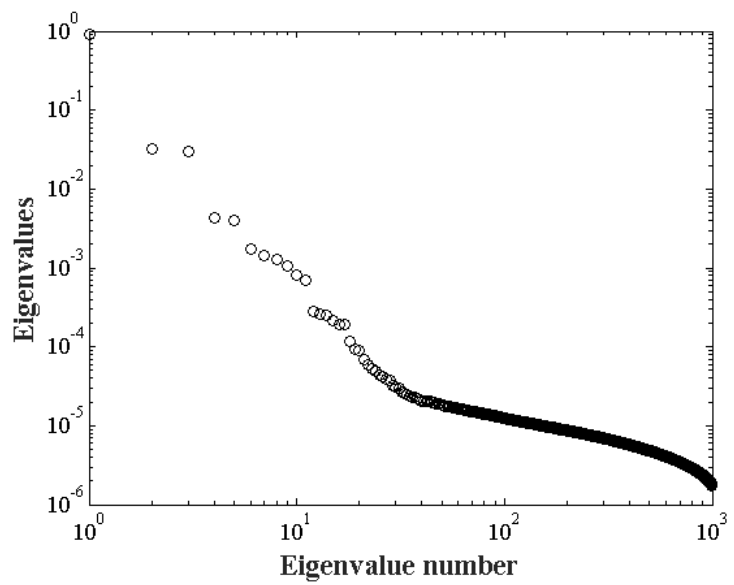


Figure 5. Eigenvalue spectrum from P.I.V. data in horizontal plane (Operating conditions: horizontal measurement at plane $z=1.5 \mathrm{~mm}, \mathrm{Q}=50 \mathrm{~L} / \mathrm{h}$, fluid: Breox40\%w/w, $\mu=0.85$ Pa.s, $\operatorname{Re}_{\text {Mixing }}=42$ and $\mathrm{T}=20^{\circ} \mathrm{C}$, data acquisition rate: $15 \mathrm{~Hz}, 1000$ pairs of images)

First mode analysis: the mean flow

The eigenvector corresponding to mode 1 is plotted in Figure 6(a). The instantaneous velocity field associated with the first mode is given by:

$$
\overrightarrow{V_{k}^{(1)}}(x, y, t)=a_{k}^{(1)}(t) \Phi^{(1)}(x, y)
$$

for each $k$ realization of the velocity. Figure $6(b)$ plots the probability density function (pdf) of coefficient $a_{k}^{(1)}$. This coefficient is given by

$$
a_{k}^{(1)}=\left(\overrightarrow{V_{k}}, \overrightarrow{\Phi^{(1)}}\right)
$$

It can be normalized by the square root of the first eigenvalue $\lambda_{R}^{(1)}$ expressed in $\mathrm{m}^{2} / \mathrm{s}^{2}$. The first remark is that the pdf is centered on the unity value; the second remark is that the dispersion of the $\mathrm{N}$ realizations $a_{k}^{(1)}$ is low, meaning that $a_{k}^{(1)}$ is almost constant. The velocity field associated with the first mode can thus be reconstructed as:

$$
\overrightarrow{V_{k}^{(1)}}(x, y, t)=\sqrt{\lambda_{R}^{(1)}} \overrightarrow{\phi^{(1)}}(x, y) \cong c s t \quad \forall k
$$

This reconstructed velocity field is close to the mean velocity according to many studies concerning P.O.D. analysis. We thus believe that the first mode is a steady-state field corresponding to the mean flow, as confirmed by Figure 6(c). 


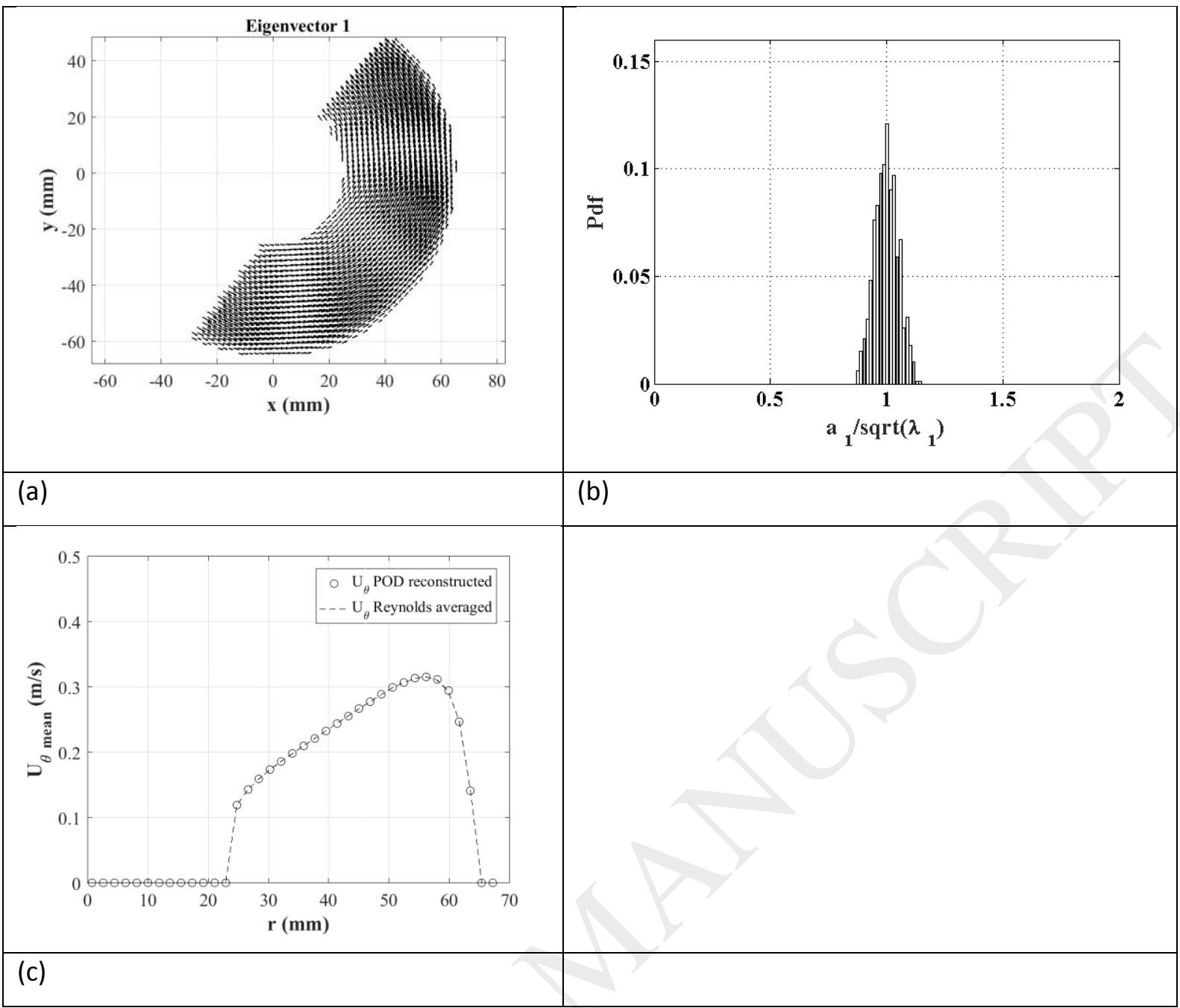

Figure 6. First mode (a) eigenvector, (b) pdf of normalized P.O.D. coefficient and (c) reconstructed radial profile of tangential velocity compared to averaged profile

\section{Organized motion}

As mentioned above, the eigenvalues $\lambda_{R}^{(2)}$ and $\lambda_{R}^{(3)}$ have similar orders of magnitude, which suggests that they may correspond to organized motions and that the two modes are somehow related. The eigenvectors corresponding to modes $2, \overrightarrow{\phi^{(2)}}(x, y)$ and $3, \overrightarrow{\phi^{(3)}}(x, y)$, are plotted in Figure 7 (a) and (c). The structures visible in these two modes exhibit wavelengths and structures similar to the shape of the impeller, suggesting some organization in the flow. Once again, these plots are not velocity fields. The velocity fields associated with the sum of these modes can be written: 


$$
\overrightarrow{V_{k}^{(2,3)}}(x, y, t)=\sum_{I=2}^{3} \overrightarrow{V_{k}^{(()}}(x, y, t)=a_{k}^{(2)}(t) \overrightarrow{\phi^{(2)}}(x, y)+a_{k}^{(3)}(t) \overrightarrow{\phi^{(3)}}(x, y)
$$

where the coefficients are again given by

$$
a_{k}^{(2)}=\left(\overrightarrow{V_{k}}, \overrightarrow{\Phi^{(2)}}\right) \quad \text { and } \quad a_{k}^{(3)}=\left(\overrightarrow{V_{k}}, \overrightarrow{\Phi^{(3)}}\right)
$$

Figure 7 (b) and (d) show the probability density function of the normalized coefficients $a_{k}^{(2)} / \sqrt{\lambda_{R}^{(2)}}$ and $a_{k}^{(3)} / \sqrt{\lambda_{R}^{(3)}}$. The distributions are centered on the origin and their shape can be related to a sinusoidal distribution, as expected from the literature.

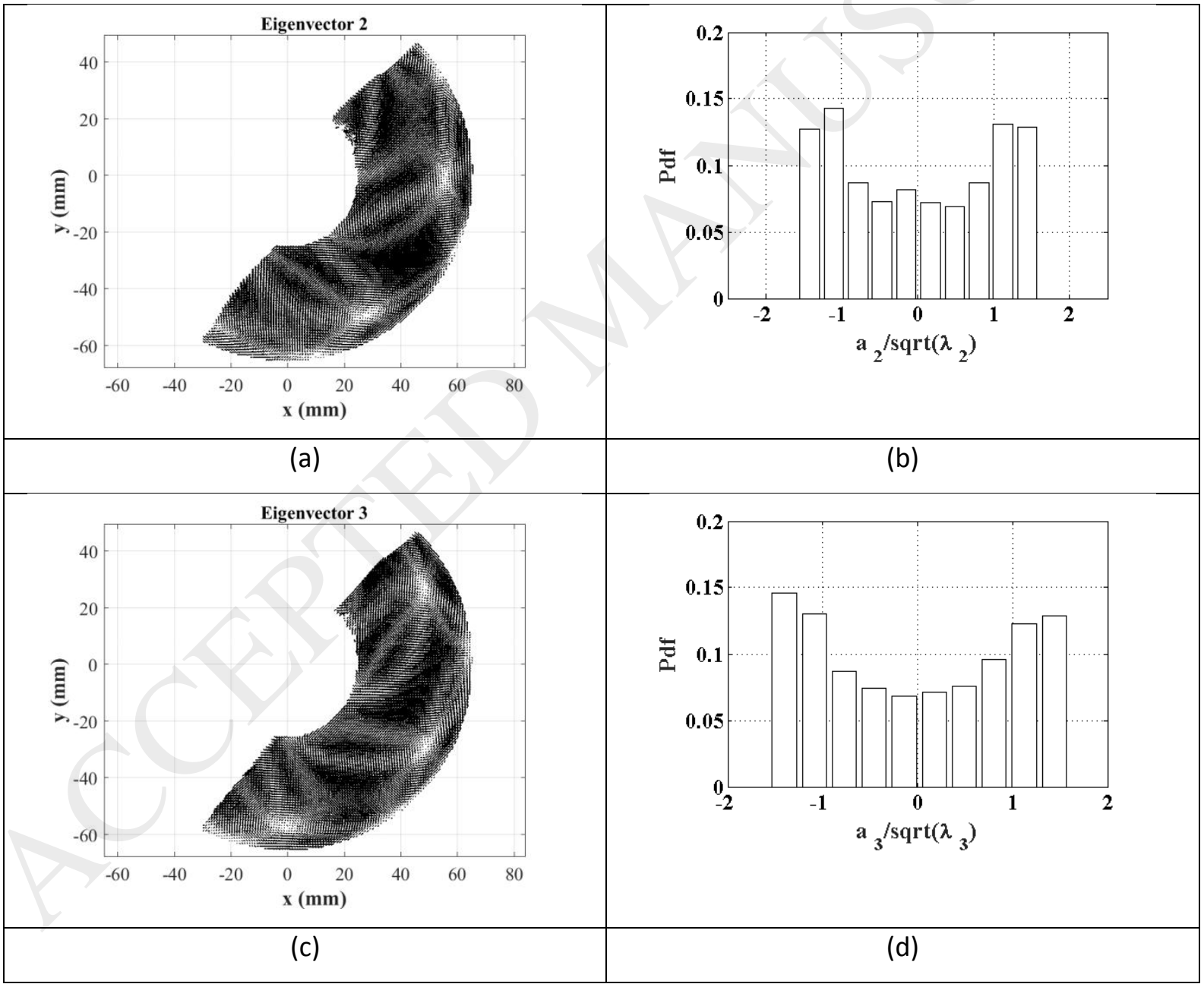

Figure 7. (a), (c) Second and third mode eigenvectors and (b), (d) pdf of normalized P.O.D. coefficient 
In order to highlight the link between modes 2 and 3, the k realizations of P.O.D. coefficients $a_{k}^{(2)}$ are plotted versus the k realizations of P.O.D. coefficients $a_{k}^{(3)}$ in Figure 8(a). A 2D projection of the phase portrait in the $\left(a_{k}^{(2)}, a_{k}^{(3)}\right)$ plane is thus obtained. The set of data shows an organized shape, which, for the sake of simplicity, will be considered as an ellipse. The coefficients can thus be related by the expression:

$$
\frac{a_{k}^{(2)^{2}}}{2 \lambda_{R}^{(2)}}+\frac{a_{k}^{(3)^{2}}}{2 \lambda_{R}^{(3)}}=1
$$

where the eigenvalues are expressed in $\mathrm{m}^{2} / \mathrm{s}^{2}$. The periodic nature of these coherent structures associated with modes 2 and 3 can be expressed as sinusoidal variations (Ducci et al., 2007, Doulgerakis et al., 2011, Gabelle et al., 2013).

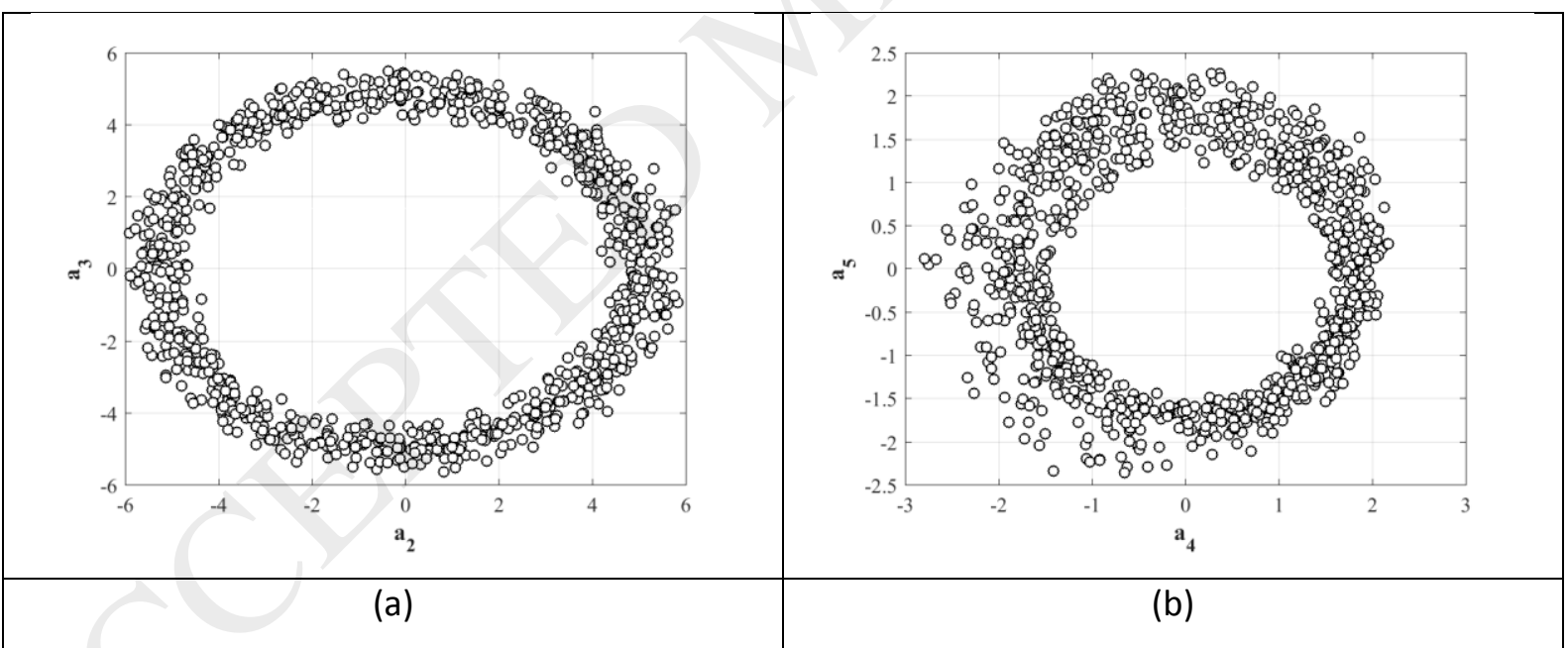

Figure 8. Portrait of phase between coefficients of modes 2 and 3 (a) and 4 and 5 (b)

As mentioned previously, the eigenvalues $\lambda_{R}^{(4)}$ and $\lambda_{R}^{(5)}$ also have similar orders of magnitude and may thus contribute to organized motion. The eigenfunctions corresponding to mode $4, \overrightarrow{\phi^{(4)}}(x, y)$ and 5 , 
$\overrightarrow{\phi^{(5)}}(x, y)$, are plotted in Figure 9. Compare to modes 2 and 3, modes 4 and 5 again show vortex structures but the length-scale seems to be roughly half the length-scales of modes 2 and 3 . The probability density function of the normalized coefficients $a_{k}^{(4)} / \sqrt{\lambda_{R}^{(4)}}$ and $a_{k}^{(5)} / \sqrt{\lambda_{R}^{(5)}}$ can be plotted. Their distributions are centered on the origin, whereas the pdf distributions reveal a slightly noisy sinusoidal shape.

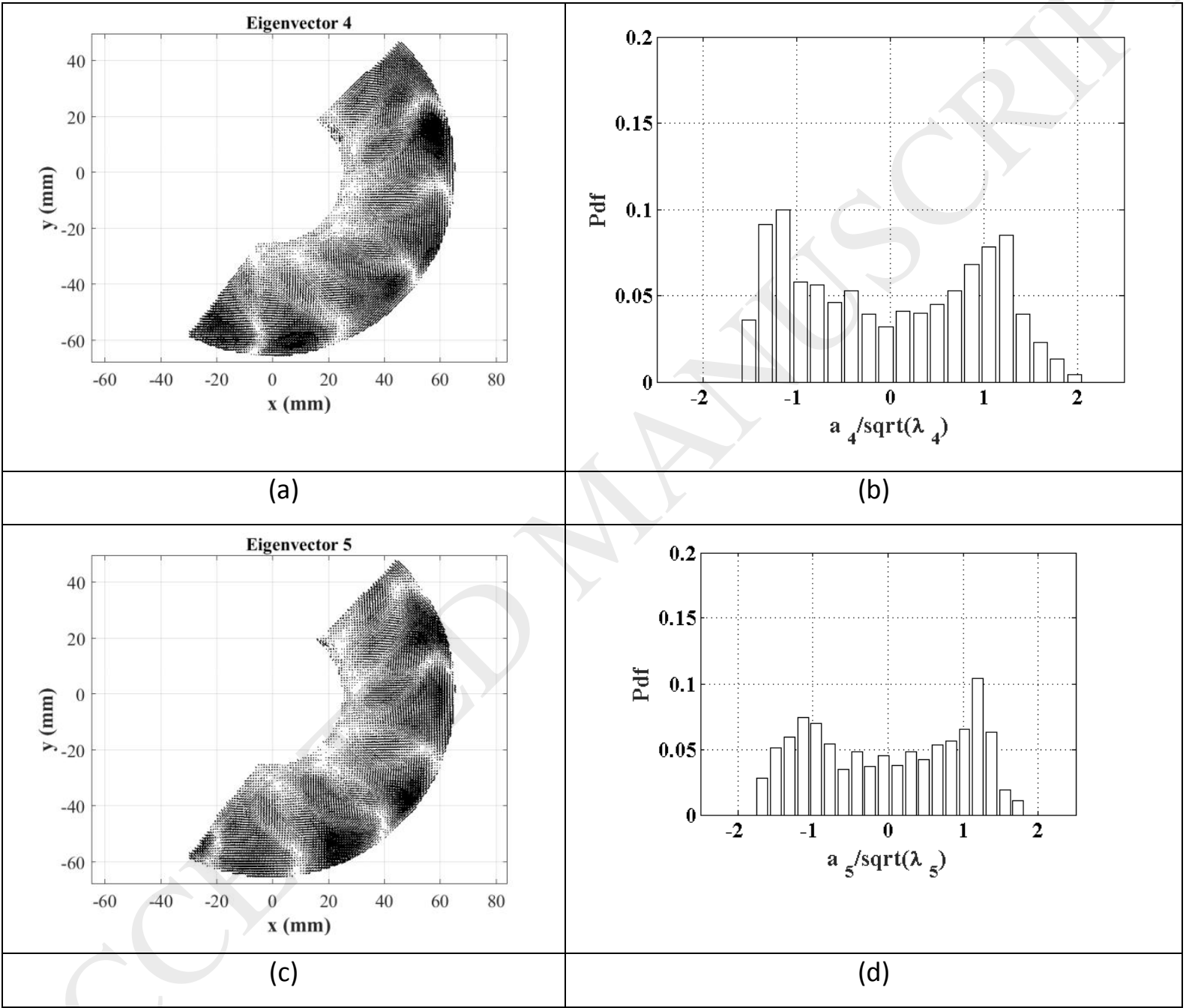

Figure 9. Fourth and fifth mode (a), (c) eigenfunctions, and (b, d) pdf of normalized P.O.D. coefficient Similarly to the previous analysis of modes 2 and 3, the k realizations of $a_{k}^{(4)}$ are plotted versus the $\mathrm{k}$ realizations of $a_{k}^{(5)}$ in Figure 8(b) and exhibit a strong relation between modes 4 and 5 although the pdf distributions reveal a noisy sinusoidal distribution. 
From these results, it is possible to reconstruct the organized motion based on modes 2 to 5 .

Each instantaneous velocity field can be reconstructed as:

$$
\overrightarrow{V_{\text {org_k }_{-}}}(x, y)=\sum_{I=2}^{N 5} a_{k}^{(I)} \overrightarrow{\Phi^{(I)}}(x, y)
$$

For example, the instantaneous radial profile of tangential velocity can be plotted (Figure 10).

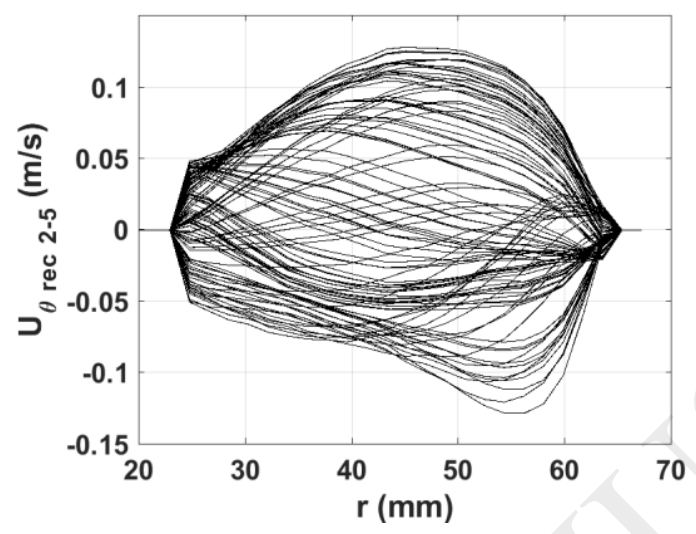

Figure 10. Reconstructed instantaneous radial profile of tangential velocity

These instantaneous velocity profiles clearly highlight the periodic motion induced by the rotation of the impeller blades. From these instantaneous velocity profiles, it is possible to estimate the associated viscous shear rate and its root mean square profile.

\section{Vertical profile of fluctuating tangential velocity}

Similar data processing can be performed in the vertical planes. Below, we follow the analysis of horizontal P.I.V. planes. Before processing the data, it is necessary to specify that the P.I.V. domain analysis will be limited in the vertical direction to positions located above the impeller and in the horizontal direction to positions close to the center of the image. In fact, the P.I.V. vertical planes analyzed with the P.I.V. are tangent to the radial velocity in a limited region close to the center of the image. For these reasons, the number of vectors will be much smaller than in the horizontal planes.

First, the eigenvalue spectrum is plotted in Figure 11. Here again, the first mode is the most energetic and the second and third are two orders of magnitude smaller. 


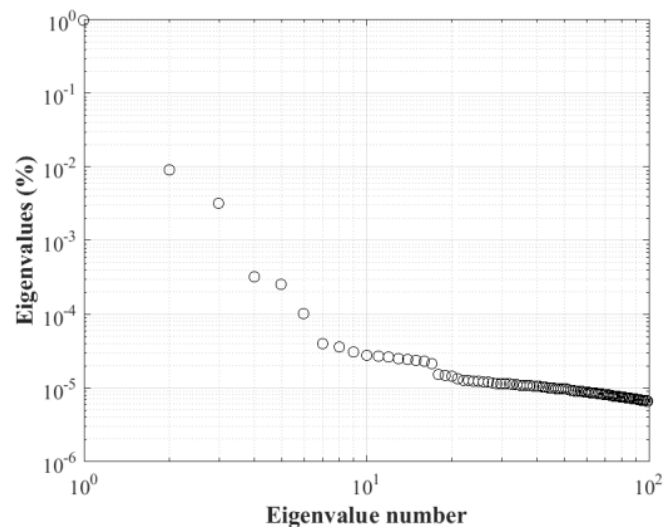

Figure 11. Eigenvalue spectrum from P.I.V. data in vertical plane. (Operating conditions: vertical measurement at radius $r=65 \mathrm{~mm}, \mathrm{Q}=50 \mathrm{~L} / \mathrm{h}$, fluid: Breox $40 \% \mathrm{w} / \mathrm{w}, \mu=0.85$ Pa.s, $\operatorname{Re}_{\text {Mixing }}=42$ and $\mathrm{T}=$ $20^{\circ} \mathrm{C}$, data acquisition rate: $15 \mathrm{~Hz}, 3000$ pairs of images.)

\section{Eigenvectors and associated P.O.D. coefficients}

Figure 12 shows the first three eigenvectors and the histograms of the associated coefficients.

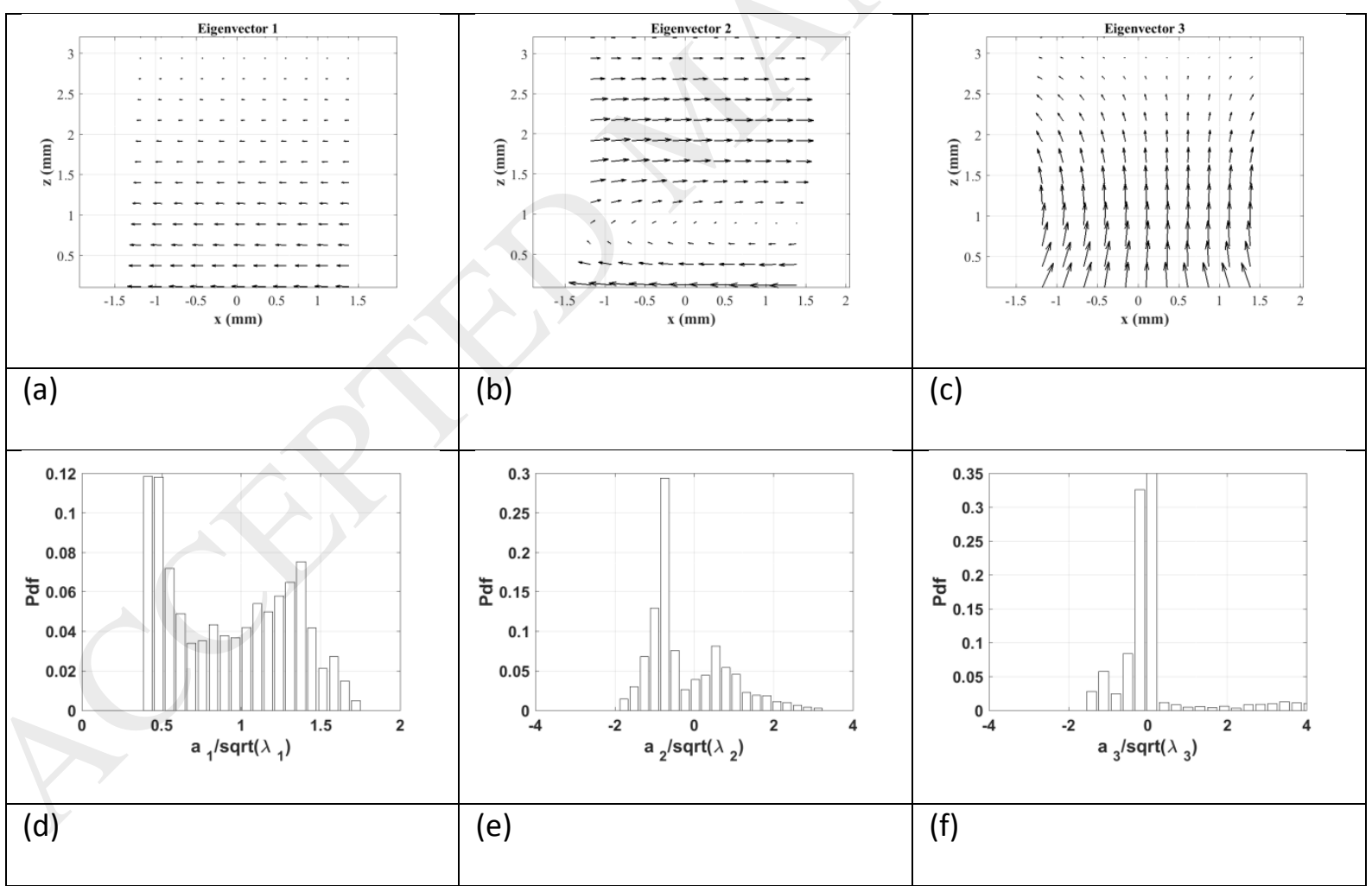

Figure 12. Eigenvectors ( $a, b$ and $c$ ) and histograms ( $d$, e and $f$ ) of the associated coefficients for modes 1 to 3 from P.O.D. data in a vertical plane 
The first mode (Figure 12 (a)) corresponds to the mean flow; the vertical profile of tangential velocity is linear as reported in $\S 3.1$. However, the histogram of coefficient $a_{1}$ is less centered on a fixed value. The second mode illustrates the existence of secondary flows induced by the impeller blade rotation; the histogram exhibits values centered on zero and its shape combines sinusoidal and random trends. The third mode also contributes to secondary flows, but the histogram of $a_{3}$ coefficients is more random than sinusoidal.

From these data, the organized motion can be reconstructed. Vertical profiles of tangential and vertical velocity components are plotted in Figure 13.

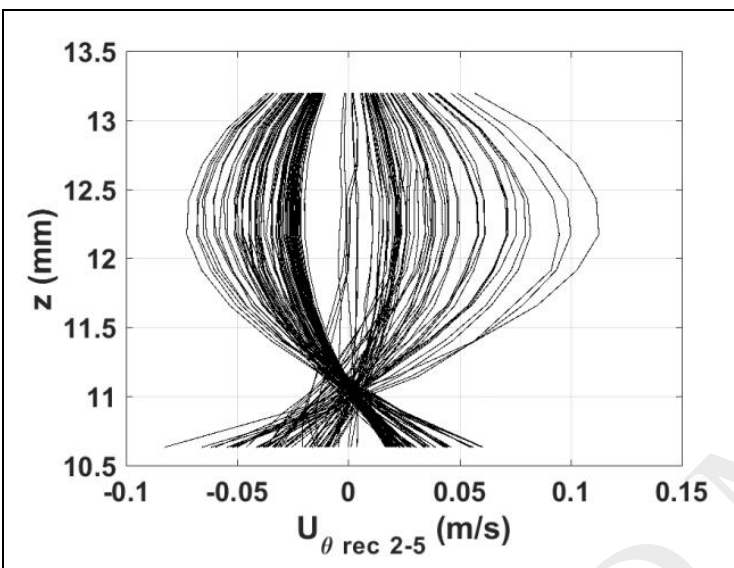

(a)

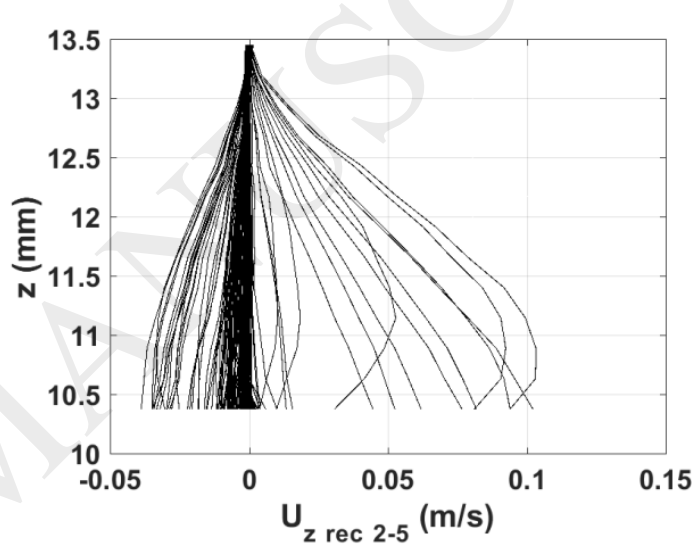

(b)

Figure 13. Vertical profiles of instantaneous (a) tangential and (b) vertical fluctuating velocity profiles from P.O.D. reconstruction in a vertical plane

Here again, the instantaneous velocity profiles clearly highlight the periodic motion induced by the rotation of the impeller blades. From these instantaneous velocity profiles, the associated viscous shear rate and its root mean square profile can be estimated.

\subsection{Mean shear stress versus r.m.s. shear stress}

The data processing was applied to different impeller frequencies. The radial profiles of both mean wall shear stress and root mean square fluctuating wall shear stress were estimated from P.I.V. data processed in a vertical plane and are plotted in Figure 14. The mean wall shear stress increases slightly with the radial position and increases almost linearly with the impeller frequency. We have seen that the vertical velocity profile above the disk is linear between the disk velocity and the static 
wall. The wall shear stress is thus linearly related to the disk velocity, which is proportional to $\mathrm{r} \omega$. Thus the wall shear stress is expected to vary linearly with the frequency. Similarly, the root mean square fluctuating wall shear stress increases almost linearly with the impeller frequency. Such results are important and necessary to understand the role of transient hydrodynamics in limiting fouling in dynamic systems, since we were able to quantify both mean and root mean square fluctuating wall shear stresses. However, it is difficult to conclude on which physical phenomenon is the strongest. The dynamic filtration concept suggests that root mean square fluctuating wall shear stress should play a key role since it is related to the impeller blade periodic motion but additional research work is needed to support this idea. It will focus on different impeller shapes, including those with similar surface area but different numbers of blades. Thus, increasing the frequency of the blade passage would enable us to quantify how the intermittence induced by the dynamic impeller decreases the fouling of the system.

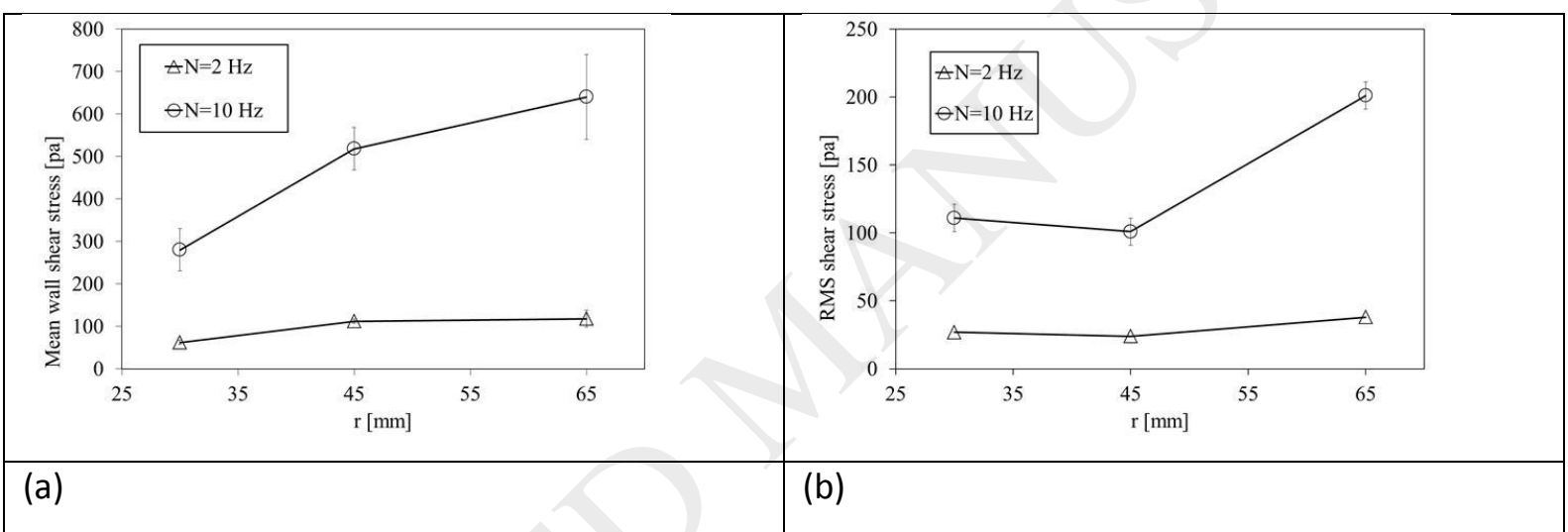

Figure 14. Radial profiles of mean wall shear stress and root mean square fluctuating wall shear stress estimated from P.I.V. data processed in a vertical plane at two impeller rotation frequencies $(\mathrm{N}=2 \mathrm{~Hz}$ and $\mathrm{N}=10 \mathrm{~Hz})$

\section{Conclusion}

In conclusion, P.I.V. data were processed to obtain both mean velocity profiles, in terms of radial profiles and vertical profiles, and mean shear stress profiles

From these profiles, it was possible to estimate wall shear stress distributions along the upper and lower boundaries as well as along the external cylinder, with the associated torque. The total torque 
was then estimated. Considering angular momentum balance, the torque along the rotating impeller was deduced and the associated power was calculated. The power number resulting from this analysis was compared to global values estimated previously and comparisons were more than satisfactory. In addition, the analysis of the local hydrodynamics gave a better understanding of how the flow was organized and how the wall shear stresses and corresponding torques were distributed. The main contribution was due to the upper and lower wall ( $40 \%$ each), the lateral (external) wall contributing $20 \%$.

Finally, the fluctuating part of the velocity was investigated. P.O.D. enabled such organized motion to be reconstructed, based on modes 2 to 5 . Both fluctuating velocity fields and shear stresses were estimated. The root mean square of fluctuating wall shear stresses was calculated and was shown to be quite high - up to $45 \%$ of the mean value. Consequently, the periodic fluctuations of the wall shear stress induced by the impeller motion may help to limit fouling.

\section{Acknowledgements}

Financial support from the China Scholarship Council is gratefully acknowledged (grant No. 201304490066). The authors wish to thank José Moreau and Bernard REBOUL (LISBP) for their contribution to the mechanical part and Pascal DEBREYNE (PIHM, Lille) for data acquisition and the electrical control of the experimental setup. 


\section{References}

Akoum, O., Richfield, D., Jaffrin, M.Y., Ding, L.H., Swart, P., 2006. Recovery of trypsin inhibitor and soy milk protein concentration by dynamic filtration. Journal of Membrane Science 279, 291-300. doi:10.1016/j.memsci.2005.12.030

Berkooz G., Holmes P., Lumley J.L., 1993. Proper orthogonal decomposition in the analysis of turbulent flows. Annual Review of Fluid Mechanics. 25 539-575.

Bott, R., Langeloh, T., Ehrfeld, E., 2000. Dynamic cross flow filtration. Chemical Engineering Journal 80, 245-249. doi:10.1016/S1383-5866(00)00097-6

Bugay S., Escudié R., Liné A., Experimental analysis of hydrodynamics in axially agitated tank using P.I.V. technique, AIChE Journal, 48(3), pp 463-475, 2002

Calaf M., Hultmark M., Oldroyd H.J., Simeonov V., Parlange M.B., Coherent structures and the k 1 spectral behavior, Physics of fluids, 25, 125107, 2013.

Chang, A.G.F.A.S., 2008. Techniques to Enhance Performance of Membrane Processes, in: Handbook of Membrane Separations. pp. 1-40.

De Angelis E., Casciola C.M., L'vov V.S., Piva R., Procaccia I., 2003. Drag reduction by polymers in turbulent channel flows: energy redistribution between invariant empirical modes. Phys. Rev. E 67 050612.

Ducci A., Doulgerakis Z., Yianneskis M., 2007. Decomposition of Flow Structures in Stirred Reactors and Implications for Mixing Enhancement. Ind. Eng. Chem. Res. 47 3664-3676.

Doulgerakis Z., 2010. Large scale vortex and strain dynamics in mixing vessels and implications for macro-mixing enhancement, PhD thesis, King's College, University of London, UK.

Doulgerakis Z., Yianneskis M., Ducci A., 2011. On the Manifestation and nature of macroinstabilities in stirred vessels. AIChE Journal. 57 2941-2954.

Ersahin M.E., Ozgun H., Dereli R.K., Ozturk I., Roest K., van Lier J.B., 2012. A review on dynamic membrane filtration: Materials, applications and future perspectives. Bioresource Technology 122, 196-206. doi:10.1016/j.biortech.2012.03.086

Escudié R., Liné A., Experimental analysis of hydrodynamics in radially agitated tank, AIChE Journal. 49(3) pp 585-603, 2003

Figueredo Cardero A., Chico E., Castilho L., de Andrade Medronho R., Particle image velocimetry (PIV) study of rotating cylindrical filters for animal cell perfusion processes, Biotechnology Progress. 28 (2012) 1491-1498. doi:10.1002/btpr.1618.

Fillaudeau, L., Boissier, B., Moreau, A., Blanpain-Avet, P., Ermolaev, S., Jitariouk, N., Gourdon, A., 2007. Investigation of rotating and vibrating filtration for clarification of rough beer. Journal of Food Engineering 80, 206-217. doi:10.1016/j.jfoodeng.2006.05.022 
Fillaudeau L., Boissier B., Ermolaev S., Jitariouk N., Gourdon A., 2007, Etude hydrodynamique d'un module de filtration dynamique. Ind. Alim. Agri., 124 (9), 8-16.

Francis P., Martinez D.M., Taghipour F., Bowen B.D., Haynes C.A., Optimizing the rotor design for controlled-shear affinity filtration using computational fluid dynamics, Biotechnology and Bioengineering. 95 (2006) 1207-1217. doi:10.1002/bit.21090

Frenander, U., Jönsson, A.S., 1996. Cell harvesting by cross-flow microfiltration using a shear-enhanced module. Biotechnology and Bioengineering 52, 397-403. doi:10.1002/(SICI)10970290(19961105)52:3<397::AID-BIT5>3.0.CO;2-F

Gabelle J.-C., Morchain J., Anne-Archard D., Augier F., Liné A., Experimental determination of the shear rate in a stirred tank with non-Newtonian fluid, AIChE Journal, 59(6), pp 2251-2266, 2013.

Handler R.A., Housiadas K.D., Berris A.N., 2006, Karhunen-Loeve representations of turbulent channel flows using the method of snapshots, Int. J. Numer. Meth. Fluids 52 pp 1339-1360

Huuhilo, T., Väisänen, P., Nuortila-Jokinen, J., Nyström, M., 2001. Influence of shear on flux in membrane filtration of integrated pulp and paper mill circulation water. Desalination 141, 245-258. doi:10.1016/S0011-9164(01)85003-7

Jaffrin, M.Y., Ding, L.H., Akoum, O., Brou, A., 2004. A hydrodynamic comparison between rotating disk and vibratory dynamic filtration systems. Journal of Membrane Science 242, 155-167. doi:10.1016/j.memsci.2003.07.029

Jiang T., Zhang H., Yang F., Gao D., Du H., Relationships between mechanically induced hydrodynamics and membrane fouling in a novel rotating membrane bioreactor, Desalination and Water Treatment. $51(2013$, a) 2850-2861. doi:10.1080/19443994.2012.750794.

Jiang T., Zhang H., Qiang H., Yang F., Xu X., Du H., Start-up of the anammox process and membrane fouling analysis in a novel rotating membrane bioreactor, Desalination. $311(2013$, b) 46-53. doi:10.1016/j.desal.2012.10.031.

Kim, K., Jung, J.-Y., Kwon, J.-H., Yang, J.-W., 2015. Dynamic microfiltration with a perforated disk for effective harvesting of microalgae. Journal of Membrane Science 475, 252-258. doi:10.1016/j.memsci.2014.10.027

Knight B., Sirovich L., 1990. Kolmogorov inertial range for inhomogeneous turbulent flows. Physical Review Letters. 65 1356-1359.

Lee, S.S., Burt, A., Russotti, G., Buckland, B., 1995. Microfiltration of recombinant yeast cells using a rotating disk dynamic filtration system. Biotechnology and Bioengineering 48, 386-400. doi:10.1002/bit.260480411

Li T., Law A.W.-K., Cetin M., Fane A.G., Fouling control of submerged hollow fibre membranes by vibrations, Journal of Membrane Science. 427 (2013) 230-239. doi:10.1016/j.memsci.2012.09.031

Liné A., Eigenvalue spectrum versus energy density spectrum in a mixing tank, Chemical Engineering Research and Design. 108 (2016) 13-22. doi:10.1016/j.cherd.2015.10.023 
Liné A., Gabelle J.-C., Morchain J., Anne-Archard D., Augier F., On P.O.D. analysis of P.I.V. measurements applied to mixing in a stirred vessel with shear-thinning fluid, ChERD, 91, 2073-2083, 2013

Mänttäri, M., Nuortila-Jokinen, J., Nyström, M., 1997. Evaluation of nanofiltration membranes for filtration of paper mill total effluent. Filtration \& Separation 34, 275-280. doi:10.1016/S00151882(97)84794-5

Moreau J., Liné A., Proper orthogonal decomposition for the study of hydrodynamics in a mixing tank. AIChE Journal. 52 2651-2655, 2006.

Rayess, Y.E., Manon, Y., Jitariouk, N., Albasi, C., Peuchot, M.M., Devatine, A., Fillaudeau, L., 2016. Wine clarification with Rotating and Vibrating Filtration (R.V.F.): investigation of the impact of membrane material, wine composition and operating conditions. Journal of Membrane Science. doi:10.1016/j.memsci.2016.03.058

Rudolph M., Shinbrot T., Lueptow R.M., A model of mixing and transport in wavy Taylor-Couette flow, Physica D: Nonlinear Phenomena. 121 (1998) 163-174. doi:10.1016/S0167-2789(98)00149-3

Wereley S.T., Lueptow R.M., Inertial particle motion in a Taylor Couette rotating filter, Phys. Fluids. 11 (1999) 325. doi:10.1063/1.869882.

Wereley S.T., Akonur A., Lueptow R.M., Particle-fluid velocities and fouling in rotating filtration of a suspension, Journal of Membrane Science. 209 (2002) 469-484. doi:10.1016/S0376-7388(02)00365-4.

Xie X., Intensification of industrial bioprocess with dynamic filtration. PhD Thesis, INSA Toulouse, $20^{\text {th }}$ May 2017.

Xie, X., Le Men, C., Dietrich, N., Schmitz, P., Fillaudeau, L., 2017. Local hydrodynamic investigation by P.I.V. and CFD within a Dynamic filtration unit under laminar flow. Separation and Purification Technology. doi:10.1016/j.seppur.2017.04.009

Zhang, W., Ding, L., 2015. Investigation of membrane fouling mechanisms using blocking models in the case of shear-enhanced ultrafiltration. Separation and Purification Technology 141, 160-169. doi:10.1016/j.seppur.2014.11.041

Zhang H., Zhang J., Jiang W., Yang F., Du H., A new folded plate membrane module for hydrodynamic characteristics improvement and flux enhancement, Separation and Purification Technology. 154 IS (n.d.) 36-43 